\title{
A $4 \mathrm{I}$-year-old man with polyarthritis and severe autonomic neuropathy
}

\author{
Matthew E Bourcier \\ Aaron IVinik
}

Eastern Virginia Medical School, Norfolk, VA, USA
Correspondence: Matthew E Bourcier Eastern Virginia Medical School, 825 Fairfax Avenue, PO Box 1980, Norfolk,VA 23507, USA

Tel + I 757446790 I

Fax + I 7574465868

Email bourcime@evms.edu

\begin{abstract}
Orthostasis due to autonomic neuropathy can cause severe debilitation and prove refractory to treatment. This report describes a case of severe sympathetic and parasympathetic autonomic dysfunction as a consequence of acetylcholine receptor antibodies and Sjogren's syndrome. Symptomatic management, plasma fluid expanders, and IVIG therapy failed to offer a salutary response to the condition. Etanercept therapy provided improvement of the orthostasis and autonomic function measured as high and low frequency respiratory effects on heart rate variability as well as enhancement of skin blood flow using Laser Doppler. It would be of considerable interest to determine the effectiveness of etanercept in other autoimmune neuropathies.
\end{abstract}

Keywords: autonomic neuropathy, etanercept, IntraEpidermal Nerve Fibers (IENF), acetylcholine receptor antibodies, laser doppler skin blood flow, orthostasis

\section{Case presentation}

A 41-year-old gentleman with seronegative polyarthritis and Sicca syndrome developed intermittent dizziness preceding loss of consciousness within minutes after standing up. His eyes and mouth were chronically dry. He became short of breath with mild exertion and was unable to sweat. He had chronic constipation, nausea, heartburn, a poor appetite, and a 27-pound weight loss in four months. He also had constant foot pain, numbness, and swelling as if he were walking barefoot on gravel. He routinely lost sleep from persistent nocturia and noted a decrease in penile sensation with an inability to ejaculate.

He had chronic nephrolithiasis requiring lithotripsy, stent placement and removal. Echocardiography was normal. Cardiac stress testing revealed no ischemia. Chronotropic incompetence was present. Bone density scanning had a T-score of -2.3 . Computed tomography (CT) of the chest/abdomen showed a multifocal increase in lymph nodes at the celiac/superior mesenteric arteries and periaortic regions. His medications included leflunomide $20 \mathrm{mg}$ /day, vitamin D 50,000 U/week, calcium supplementation $1200 \mathrm{mg} /$ day, and daily folic acid. He was allergic to erythromycin with adverse reactions to sulfasalazine and methotrexate.

On physical examination, he was $71 \frac{1}{2}$ inches tall and weighed 164 pounds. Supine blood pressure was $128 / 78 \mathrm{mmHg}$ (pulse -65 beats per minute [bpm]) with a sitting blood pressure 118/78 mmHg (pulse - $63 \mathrm{bpm}$ ) and standing blood pressure 100/61 mmHg (pulse - 64 bpm). He was not anemic, cyanosed, jaundiced, or clubbed. Jugular venous pressure was not raised and there was no peripheral edema. Head, ears, nose, throat, and neck examinations were normal. Eye exam showed large dilated pupils that reacted poorly to light. There was no lymphadenopathy. Pectus excavatum was present. Lungs, heart, abdomen, and genitalia were normal. Musculoskeletal exam revealed swan neck deformities in the fingers. Extremity examination was normal. He had a dry, pruritic and raised erythemic rash on the face and torso. 
Cranial nerves II-XII were intact except for dilated pupils with minimal reaction to light. Muscle strength and bulk were normal. All reflexes were normal. Sensory exam in the upper extremities was unremarkable except for a decrease in prickling pain perception at the right index finger to $10 \mathrm{~cm}$. For the lower extremities, prickling pain perception was impaired to $20 \mathrm{~cm}$ on the right and $25 \mathrm{~cm}$ on the left as measured from the tip of each hallux. Soft touch, vibration perception, joint position sense, and 1-g and 10-g monofilament pressure testing were intact. Using a neuropathy scoring tool modified from Dyck and Thomas (1987) with a maximum score of 196, the total neuropathy score was 18 on the right and 16 on the left, indicating a moderate neuropathy.

On quantitative autonomic function testing (QAFT) using heart rate variability measures with an ANX 3.0 machine (Ansar Group Inc., Philadelphia, PA) all tests were abnormal with Expiration/Inspiration ratio $(\mathrm{E} / \mathrm{I}$ ratio $)=1.04$ (normal 1.2-1.6), Valsalva ratio $=1.03$ (normal 1.2-1.6), and 30:15 ratio $=1.02($ normal $1.15-1.5)$.

Quantitative sensory testing (QST) (Vinik et al 1995) in the right great toe revealed a deficit in vibration perception to 64 microns (normal 0-31 microns) and a decrease in monofilament pressure sensation to $4.21 \mathrm{log} \mathrm{g}$ (normal 0-3.95 $\log \mathrm{g})$. The warm thermal threshold on the right was $12.4^{\circ} \mathrm{C}$ (normal $0-12.4{ }^{\circ} \mathrm{C}$ ) and $13.6{ }^{\circ} \mathrm{C}$ (normal 0-12.4 ${ }^{\circ} \mathrm{C}$ ) on the left. Cold pain perception was impaired on the left great toe to $29.5^{\circ} \mathrm{C}$ (normal $0-23.3{ }^{\circ} \mathrm{C}$ ) and to $30.6{ }^{\circ} \mathrm{C}$ on the right. Heat pain perception was bilaterally impaired to $>18^{\circ} \mathrm{C}$ (normal $0-17.7^{\circ} \mathrm{C}$ ).

Laser Doppler blood flow showed decreased perfusion levels when compared with the normal range for our young population.

Electrolytes, fasting glucose/hemoglobin $\mathrm{A}_{1 \mathrm{C}}$ levels, renal/ liver function testing, lipid/thyroid panels, and prostate specific antigen scores were all normal. Erythrocyte sedimentation rates were elevated ( 28 and $48 \mathrm{~mm} / \mathrm{hr}$.) as was the C-reactive protein at $17.2 \mathrm{mg} / \mathrm{L}$. Antinuclear antibodies (ANA) screening was positive at 1:320. Rheumatoid factor and dsDNA antibodies were negative. Metabolic profile, serum protein electrophoresis, and $\mathrm{C}_{3} / \mathrm{C}_{4}$ complements were unremarkable. Vitamin D-25 was low at $17 \mathrm{ng} / \mathrm{mL}$ (normal 20-100 ng/mL).

Antibody studies with normal results included: Gastric parietal and adrenal cell antibodies, Anti-Hu, MAG IGM, GAD-65, C-ANCA, ASIALO-GM1 IGM, GD1a, GD1a IGM, GD1b IGM, and ANTI-RI (IFA). Abnormal laboratory values were: (1) acetylcholine receptor binding antibody of $0.1 \mathrm{nM} / \mathrm{L}$ (normal $<0.1 \mathrm{nM} / \mathrm{L}$ ) (2) P-ANCA positive, and (3) GD1b IGG antibody positive titer at 1:100 (normal
$<1: 100)$. N1E-115 neuroblastoma cells representing sensory and autonomic neurons were grown in-vitro in the patient's serum for four days and exhibited normal cell proliferation compared to controls (Pittenger et al 1999).

Heavy metal screens for nickel, lead, chromium, copper, and mercury proved normal. Rapid Plasma Reagin (RPR), Lyme disease titer, Hepatitis C antibody, and HIV assay were nonreactive. Cortisol, adrenocorticotropic hormone (ACTH), and aldosterone levels were all normal.

Supine norepinephrine was $66 \mathrm{pg} / \mathrm{mL}$ (normal 112-658 $\mathrm{pg} / \mathrm{mL}$ ), epinephrine $<20 \mathrm{pg} / \mathrm{mL}$, and dopamine $<30 \mathrm{pg} / \mathrm{mL}$. Standing norepinephrine was 422 pg/mL (normal 217-1109 $\mathrm{pg} / \mathrm{mL}$ ). Epinephrine and dopamine did not increase with the standing test. Supine blood pressure was 108/66 $\mathrm{mmHg}$ (pulse - $67 \mathrm{bpm}$ ). This dropped to 73/46 mmHg (pulse - 71 bpm) after one minute of standing. Supine blood pressure was $89 / 58 \mathrm{mmHg}$ at 15 minutes with the pulse staying between 70 to $72 \mathrm{bpm}$.

Electroencephalography showed abnormal bilateral midtemporal independent epileptiform discharges read as "cortical irritability." Schirmer testing and a gastric emptying study were normal. Electrophysiologic testing of peripheral nerve function of the peroneal and tibial nerves was normal.

\section{Differential diagnosis}

We suspected an autoimmune mechanism for his condition since he had Sjogren's/Sicca syndrome and autonomic nerve dysfunction, but we needed to consider other potential causes to be certain.

He did not abuse alcohol. His weight loss suggested possible malabsorptive issues such as $B_{12}$ deficiency. $B_{12}$ deficiency was excluded by the absence of macrocytic anemia and gastric parietal antibodies.

Familial amyloidosis could produce weight loss, autonomic dysfunction, and orthostatic hypotension. However, he had no family history thereof and no organomegaly. A nerve biopsy for amyloid using Congo red was negative.

Diabetes could lead to diminished peripheral blood flow, decreased intraepidermal nerve fibers (see Pathological discussion), and small fiber neuropathy (Pittenger et al 2004; Vinik et al 1995). The $\mathrm{HgA}_{1} \mathrm{C}$ and GAD-65 antibody studies were normal (Vinik et al 2005).

Chagas disease was unlikely as he had never traveled to Central or South America. A negative Lyme titer ruled out Lyme disease. The patient's RPR screen for syphilis and HIV antibody testing were both nonreactive.

Shy-Drager syndrome could present similarly but there was no parkinsonism, cerebellar ataxia, cognitive impair- 
ment, muscular atrophy, or upper motor neuron involvement (Diedrich and Robertson 2005).

While heavy metal exposure has been linked to peripheral and autonomic neuropathies, our assays for lead, mercury, nickel, chromium, and copper were normal (Rubens et al 2001).

Paraneoplastic syndrome was plausible, but there was no cerebellar ataxia, cushingoid characteristics, or visible tumors on the CT scan of the chest and abdomen. Cortisol, ACTH, and anti-Hu antibody values were likewise normal.

The clinical neuropathic syndromes associated with acetylcholine receptor antibodies and ganglionic receptor-binding antibodies could cause this (Vinik et al 2005). Reviewing the literature supported the diagnosis of autoimmune-mediated autonomic neuropathy. Sandroni and colleagues (2004) compared two sets of patients with idiopathic autonomic neuropathy: 19 who were seropositive for ganglionic acetylcoline receptor antibodies and 87 who were seronegative. There were strong associations in the seropositive group with abnormal pupillary reflexes, sicca complex, lower gastrointestinal dysfunction, bladder symptoms, and abnormal sweat testing.

\section{Proposed diagnosis}

Autoimmune-mediated autonomic neuropathy and arthritis.

\section{Pathological discussion}

Figure 1 shows skin biopsies of the forearm and proximal/distal aspects of the leg to assess nerve content. Samples were stained with protein gene product (PGP) 9.5, a fluorescent marker for intraepidermal nerve fibers (IENF). Inspection with confocal microscopy revealed a marked decrease in fluorescent nerve densities with a lack of nerve projection from the dermis into the red-stained epidermis. The patient's IENF was low at all sites -8.7 vs. $39.9 \pm 5.5$ (control) in the forearm; 4.0 vs. $18.6 \pm 4.0$ (control) in the proximal leg; and 6.2 vs. $34.7 \pm 8.1$ (control) in the distal leg. These findings support Pittenger and colleagues (2004) who previously described that a decreased IENF correlated to small-fiber neuropathy (altered warm/cold thermal sense and heat pain threshold).

\section{Management discussion}

The patient displayed strong symptomatic, objective, biochemical, and autoimmune evidence of dysautonomia. Previous therapy with leflunomide and methotrexate only provided relief for the patient's arthritic component. No targeted autonomic neuropathy treatment had been tried.

A search through the literature on the management of autoimmune-mediated autonomic neuropathy yielded no standardized guidelines.

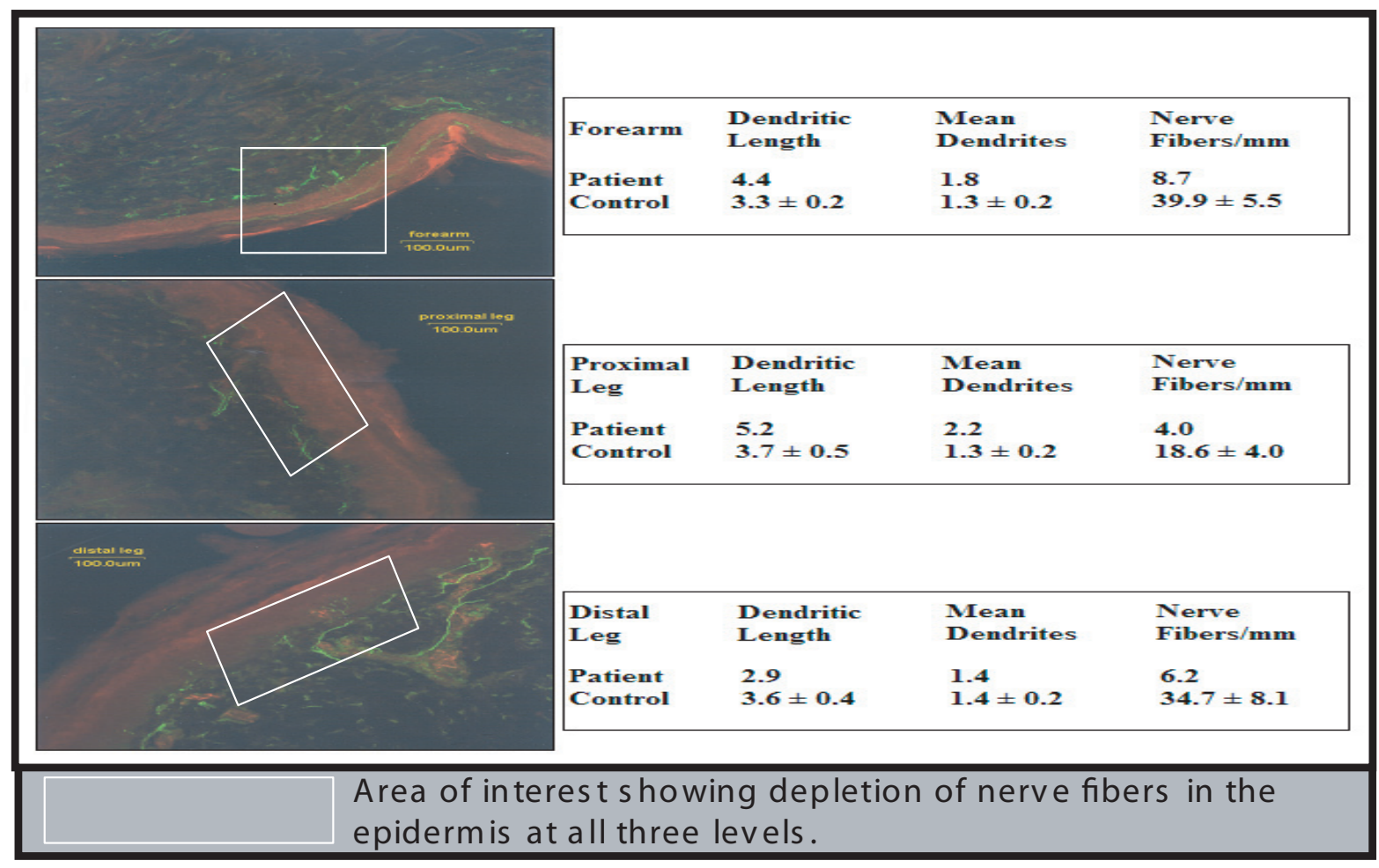

Figure I Pan-reduction of intrapidermal nerve fiber (IENF) density in the skin of the forearm, proximal leg, and distal leg with PGP 9.5 (Protein Gene Product) used as a fluorescent marker for IENF. 
The patient visited another facility for a second opinion. Their results differed from ours in one area: the acetylcholine receptor binding antibody level was $0.00 \mathrm{nmol} / \mathrm{L}$ (normal $\leq 0.02$ ). No definitive cause for the autonomic dysfunction was found and they offered treatment with 9-alpha fluoro (hydrocortisone).

The possibility of paraneoplastic syndrome remained in the differential. Multiple CT scans and a host of biochemical markers failed to support this diagnosis, yet the constellation of symptoms warranted further consideration of a neoplasm even in the absence of positive findings.

We stopped the leflunomide and addressed the orthostatic hypotension by starting florinef $0.1 \mathrm{mg}$ twice daily and prednisone $1 \mathrm{mg} /$ day to expand the plasma fluid volume (Bonnel and Graham 2004). Symptomatic relief was obtained by (1) lukewarm baths, (2) delayed transitioning to a standing position after waking, (3) use of body stockings, (4) liberal salt intake, and (5) the use of "NutriNerve" (alpha-lipoic acid, gamma linoleic acid, benfotiamine, and borage oil). We also started intravenous immunoglobulin (IVIG) therapy at $1.0 \mathrm{~g} / \mathrm{kg} /$ day for 2 days on 3 consecutive weeks.

The patient returned a year later with a broken foot from a fall. The full cycle of IVIG, florinef, and prednisone provided no symptomatic relief. The NutriNerve antioxidants were discontinued after 45 days. His examination, QAFT, QST, and blood flow analysis showed no improvement except for QST (see Table 1). This revealed the vibration, pressure perception, cold/warm sensation, and heat pain had normalized.

At that time, we considered a new therapy option: etanercept. This drug had previously been used to treat peripheral neuropathy, but its actions on autonomic neuropathy had not been documented (Sommer et al 2001). After carefully considering the risks, we started etanercept $50 \mathrm{mg} /$ week. His rheumatologist would follow him back home with the next visit here in six months.

He returned symptomatically better and recalled having just one falling episode from getting up too quickly. He gained back some of his weight, began to sweat again, and the arthritic pain and swelling had improved. A repeat chest CT scan showed a very slight decrease in the size of his lymph nodes. GAD-65 autoantibodies, acetylcholine receptor antibodies, ANA, serum ACE, vitamin D 1,25 dihydroxy, and parathyroid hormone were normal.

Symptoms continued to improve at visits four and ten months later. He discontinued the prednisone and reduced the florinef to $0.1 \mathrm{mg} /$ day. Swelling in the wrist and hand had resolved. Blood pressure readings were 148/99 $\mathrm{mmHg}$ (pulse - $66 \mathrm{bpm}$ ) for supine, 135/91 $\mathrm{mmHg}$ (pulse - $65 \mathrm{bpm}$ ) for sitting, and 90/60 mmHg (pulse - $68 \mathrm{bpm}$ ) for standing. The patient remained asymptomatic throughout these measurements.

Current QAFT, QST, and Laser Doppler blood flow analysis were compared with the baseline figures from 2004. In Figure 2, the post-etanercept basal state function remained low. Deep breathing and valsalva responses improved markedly from the baseline study. In Table 1, QST showed notable improvements in vibration, pressure, warm/cold thermal perception, and heat pain recognition after IVIG therapy. Etanercept maintained this restoration of nerve function except for heat pain recognition. In Figure 3, the Laser Doppler blood flow response increased with etanercept, as demonstrated by the upward shift of the curve during warming.

Attempts to improve autonomic function have been done using zopolrestat, an aldose reductase inhibitor (Johnson et al 2004). This drug was shown to increase cardiac output and left ventricular ejection fraction during exercise in diabetic subjects, but had no positive effect in autonomic function

Table I Quantitative sensory tests: baseline, post-IVIG, and post-etanercept treatments. Note the improvement from baseline with IVIG and etanercept in vibration and monofilament pressure perception as well as warm and cold thermal thresholds

\begin{tabular}{lllllll}
\hline Quantitative sensory tests & $\begin{array}{l}\text { Baseline } \\
\text { Left great } \\
\text { toe }\end{array}$ & $\begin{array}{l}\text { Baseline } \\
\text { Right great } \\
\text { toe }\end{array}$ & $\begin{array}{l}\text { Post-IVIG } \\
\text { Left great } \\
\text { toe }\end{array}$ & $\begin{array}{l}\text { Post-IVIG } \\
\text { Right great } \\
\text { toe }\end{array}$ & $\begin{array}{l}\text { Post-etanercept } \\
\text { Left great toe }\end{array}$ & $\begin{array}{l}\text { Post-etanercept } \\
\text { Right great toe }\end{array}$ \\
\hline $\begin{array}{l}\text { Vibration (microns) } \\
\text { Pressure (Semmes-Weinstein }\end{array}$ & 30.37 & 64.27 & 19.70 & 24.47 & 28.53 & 15.23 \\
$\begin{array}{l}\text { Monofilaments) } \\
\text { Cold sensation (below } 32^{\circ} \mathrm{C} \text { ) }\end{array}$ & 7.4 & 4.21 & 2.64 & 3.12 & 2.83 & 2.93 \\
Warm sensation (above $32^{\circ} \mathrm{C}$ ) & 13.6 & 10.4 & 2.9 & 3.6 & 3.1 & 10.9 \\
Cold pain (below $32^{\circ} \mathrm{C}$ ) & 29.5 & 12.4 & 11.4 & 6.9 & 11.7 & 8.9 \\
Heat pain (above $32^{\circ} \mathrm{C}$ ) & $>18.0$ & 30.6 & 32.0 & 26.7 & 32.0 & 32.0 \\
\hline
\end{tabular}

Normal Ranges - Vibration (0-31 microns); Pressure (0-3.95 log g); Cold Sensation (0-10.5 $\left.{ }^{\circ} \mathrm{C}\right)$; Warm Sensation $\left(0-12.4^{\circ} \mathrm{C}\right)$; Cold Pain $\left(0-23.3^{\circ} \mathrm{C}\right)$; and Heat Pain $\left(0-17.7^{\circ} \mathrm{C}\right)$. 


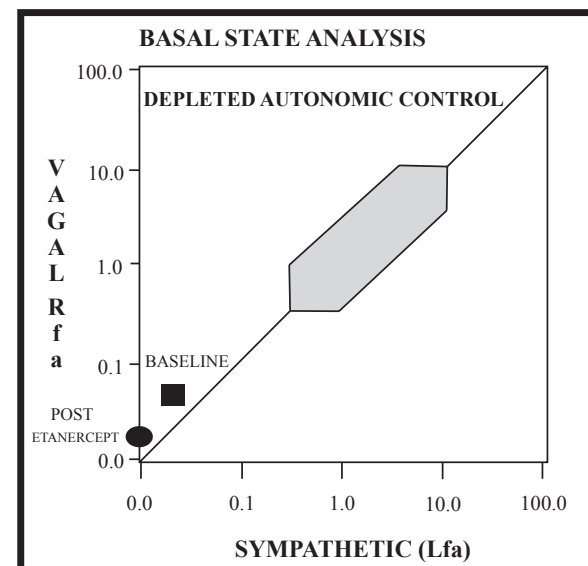

BASAL STATE - INDICATIVE OF SYMPATHETIC AND PARASYMPATHETIC FUNCTION

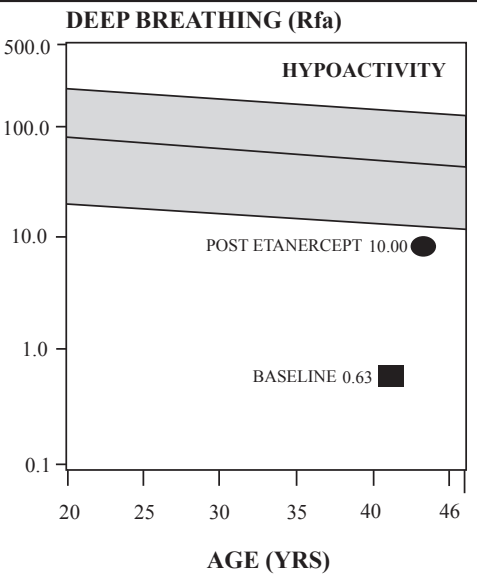

DEEP BREATHING - REPRESENTING PARASYMPATHETIC FUNCTION

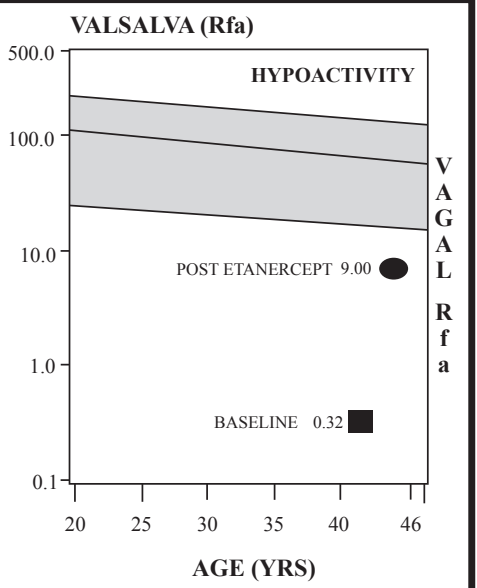

VALSALVA MANEUVER - SHOWING SYMPATHETIC FUNCTION

Figure 2 Baseline and post-etanercept quantitative autonomic function tests demonstrating severe reduction in vagal sympathetic tone. Note the improvement in deep breathing and Valsalva responses after etanercept treatment.

based on heart rate variability (Johnson et al 2004). A number of other interventions such as graded exercise, ace inhibitors, and spironolactone have been tried with limited success (Kontopoulos et al 1997; Gaede et al 1999; Korkmaz et al 2000). Our patient's QAFT demonstrated recovery of sympathetic (Valsalva) and parasympathetic (deep breathing) function with etanercept as well as an enhancement of peripheral skin blood flow on Laser Doppler studies.

The initial improvement of this patient's autonomic symptoms could have also resulted from the use of alpha-lipoic acid and benfotiamine in the antioxidant mixture (Casellini and Vinik 2007). In particular, $600 \mathrm{mg}$ /day of alpha-lipoic acid has been shown to improve diabetic polyneuropathy (including clinical and symptomatic improvement of C-fiber neuropathy, which is also implicated in autonomic dysfunction) in a 1,258 patient meta analysis and in the SYDNEY 2 trial involving 181 subjects (Ziegler et al 2004, 2006). It has been suggested that these changes may be related to the antioxidant effects on enhanced nerve blood flow (Coppey et al 2001; Ziegler et al 2006). Since our patient stopped NutriNerve after only

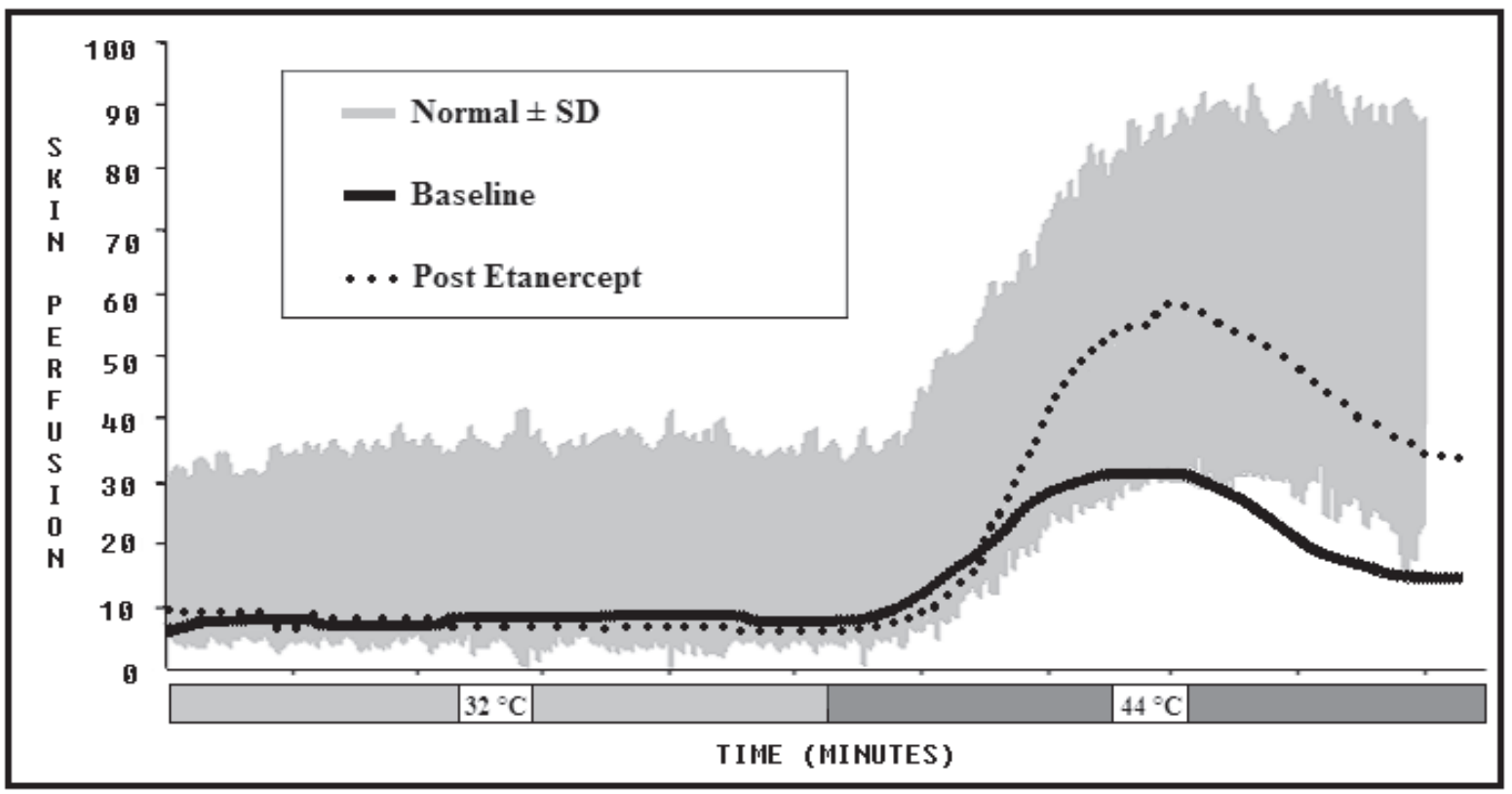

Figure 3 Laser Doppler perfusion response to heating for baseline and post-etanercept treatment. The grey area is normal. 
a month and a half, we conclude his continued improvement in autonomic function is from the etanercept.

\section{Final diagnosis}

Idiopathic autoimmune-mediated autonomic neuropathy and arthritis improved with etanercept.

\section{Disclosure}

The authors report no conflicts of interest in this work.

\section{References}

Bonnel RA, Graham DJ. 2004. Peripheral neuropathy in patients treated with leflunomide. Clin.Pharmacol Ther, 75:580-5.

Casellini CM, Vinik AI. 2007. Clinical manifestations and current treatment options for diabetic neuropathies. Endocr Pract, 13:550-66.

Coppey LJ, Gellett JS, Davidson EP, et al. 2001. Effect of antioxidant treatment of streptozotocin-induced diabetic rats on endoneurial blood flow, motor nerve conduction velocity, and vascular reactivity of epineurial arterioles of the sciatic nerve. Diabetes, 50:1927-37.

Diedrich A, Robertson D. 2005. Multiple system atrophy [online]. Accessed on October 28, 2006. URL: http://www.emedicine.com/neuro/topic671. htm.

Dyck PJ, Thomas PK. 1987. Diabetic Neuropathy. Philadelphia, PA: W. B. Saunders Company.

Gaede P, Vedel P, Parving HH, et al. 1999. Intensified multifactorial intervention in patients with type 2 diabetes mellitus and microalbuminuria: the Steno type 2 randomized study. Lancet, 353:617-22.

Johnson BF, Nesto RW, Pfeifer MA, et al. 2004. Cardiac abnormalities in diabetic patients with neuropathy: effects of aldose reductase inhibitor administration. Diabetes Care, 27:448-54.
Kontopoulos AG, Athyros VG, Didangelos TP, et al. 1997. Effect of chronic quinapril administration on heart rate variability in patients with diabetic autonomic neuropathy. Diabetes Care, 20:335-61.

Korkmaz ME, Muderrisoglu H, Ulucam M, et al. 2000. Effects of spironolactone on heart rate variability and left ventricular systolic function in severe ischemic heart failure. Am J Cardiol, 86:649-53.

Pittenger GL, Malik RA, Burcus N, et al. 1999. Specific fiber deficits in sensorimotor diabetic polyneuropathy correspond to cytotoxicity against neuroblastoma cells of sera from patients with diabetes. Diabetes Care, 22:1839-44.

Pittenger GL, Ray M, Burcus NI, et al. 2004. Intraepidermal nerve fibers are indicators of small-fiber neuropathy in both diabetic and nondiabetic patients. Diabetes Care, 27:1974-9.

Rubens O, Logina I, Kravale I, et al. 2001. Peripheral neuropathy in chronic occupational inorganic lead exposure: a clinical and electrophysiological study. J Neurol Neurosurg Psychiatry, 71:200-4.

Sandroni P, Vernino S, Klein CM, et al. 2004. Idiopathic autonomic neuropathy: comparison of cases seropositive and seronegative for ganglionic acetylcholine receptor antibody. Arch Neurol, 61:44-8.

Sommer C, Schafers M, Marziniak M, et al. 2001. Etanercept reduces hyperalgesia in experimental painful neuropathy. J Peripher Nerv Syst, 6:67-72.

Vinik AI, Anandacoomaraswamy D, Ullal J. 2005. Antibodies to neuronal structures: Innocent bystanders or neurotoxins? Diabetes Care, 28:2067-72.

Vinik AI, Suwanwalaikorn S, Stansberry KB, et al. 1995. Quantitative measurement of cutaneous perception in diabetic neuropathy. Muscle Nerve, 18:574-84.

Ziegler D, Ametov A, Barinov A, et al. 2006. Oral treatment with alphalipoic acid improves symptomatic diabetic polyneuropathy: the SYDNEY 2 trial. Diabetes Care, 29:2365-70.

Ziegler D, Nowak H, Kempler P, et al. 2004. Treatment of symptomatic diabetic polyneuropathy with the antioxidant alpha-lipoic acid: a metaanalysis. Diabet Med, 21:114-21. 
